\title{
Interaction between physical, psychosocial, and organisational work factors for low back symptoms and its consequences amongst In- donesian coal mining workers
}

\author{
Baiduri Widanarko ${ }^{\mathrm{a}, \mathrm{d}, *}$, Stephen Legg $^{\mathrm{a}}$, Mark Stevenson ${ }^{\mathrm{b}}$, Jason Devereux ${ }^{\mathrm{c}}$ \\ ${ }^{a}$ Centre for Ergonomics, Occupational Safety and Health, School of Management, College of Business, Massey \\ University, Private Bag 11222, Palmerston North 4442, New Zealand \\ ${ }^{b}$ EpiCentre, Institute of Veterinary, Animal and Biological Sciences, College of Sciences, Massey University, \\ Palmerston North, New Zealand \\ ${ }^{c}$ Business Psychology Unit, Department of Psychology, University College London, UK \\ ${ }^{d}$ Department of Occupational Health and Safety, Faculty of Public Health, Universitas Indonesia, Depok 16424, \\ Indonesia
}

\begin{abstract}
Although there is strong evidence that single physical, psychosocial and organisational risk factors are each independent predictors of low back symptoms (LBS) and its consequences, little is known about their combination/interaction. A preliminary study was conducted among 673 workers as part of a larger study $(n=1294)$ in a coal mining company in Indonesia. A self-reported questionnaire was used to obtain physical and psychosocial exposures, and organisational factors. Each participant was grouped into one of four combination exposure groups: 1) high physical (working with bent trunk, whole body vibration exposure, lifting) and high psychosocial (high effort, low reward, work stress), 2) high physical and low psychosocial, 3) low physical and high psychosocial, 4) low physical and low psychosocial (as the reference group). Individuals in the high physical and high psychosocial group were the most likely to report LBS (OR 3.47 95\% CI 1.816.64), reduced activities (OR 6.94 95\% CI 1.58-30.49) and absenteeism (OR 7.01 95\% CI 2.04-24.10). Permanent workers were more likely to report LBS and its consequences whereas night shift work increased the risk of LBS consequences. Interventions to reduce LBS and its consequences should address both physical and psychosocial factors, with a focus on permanent and night shift workers.
\end{abstract}

Keywords: musculoskeletal disorders; back pain; developing country; blue-collar worker; disability; sick leave

*Corresponding author. Email: baiduri@ui.ac.id or B.Widanarko@massey.ac.nz $1051-9815 / 12 / \$ 27.50 @ 2012$ - IOS Press and the authors. All rights reserved 


\section{Introduction}

Many studies have shown that physical, psychosocial, and organisational factors are risk factors for LBS and its consequences. Physical risk factors that have been identified in various occupational groups include trunk bending and/or twisting [1-8], lifting [2, 3, 5-7, 9-12], and whole body vibration [13-15]. Psychosocial risk factors include high job strain [4], low job control [4], high psychological demands [2, $4,5,10]$, low skill discretion [2], low decision latitude $[5,16]$, low social support $[2,5,8,17,18]$, job dissatisfaction $[2,7,18,19]$, high effort-reward imbalance (ERI) $[6,20]$ and high work stress [21].

The evidence for associations between organisational risk factors and LBS and its consequences is less well studied and hence less clear. A crosssectional study found that night shift workers were more likely to report LBS than day shift workers [22]. Schneider et al. [23] reported that part-time employees were less likely to report LBS than fulltime employees. In contrast, Devereux et al. [21] showed that hours worked per week or shift work did not increased the risk of LBS.

Various physical and psychosocial risk factors are known to be predictors for LBS but there may be combinations/interactions that may influence each other $[24,25]$. To our knowledge only five studies $[14,21,26-28]$ have investigated physical and psychosocial risk factor combinations/interactions with LBS. All of these have been conducted in developed countries and have shown that individuals exposed to both high physical and high psychosocial factors have the highest risk of LBS. They also indicated that physical factors appear to be more prominent than psychosocial factors in increasing the risk of LBS. As far as we are aware, there are no previous studies that have examined these combinations/interactions in industrially developing countries (IDCs). Thus, the objective of the present study was to examine the combination of physical and psychosocial risk factors for LBS and its consequences in term of reduced activities and absenteeism in an IDC.

\section{Methods}

The study was conducted in a large coal mining contractor company in Indonesia. In this preliminary study, invitations to participate were delivered in person to 1300 coal mining workers involved in light and heavy physical workloads at one site (located in a province of East Borneo).

\subsection{Questionnaire}

A self-administered questionnaire was used to obtain information on physical, psychosocial, and organisational factors, LBS, demographic characteristics (age and gender) and any accident(s) that involved the low back region. Since the original questions were in English and the study was conducted in Indonesia(n), a cross-cultural adaptation of the questionnaire was undertaken [29].

Physical exposures for their current working place were assessed by asking participants to estimate how much working time during their work activities they were involved in any of these situations: sitting position [30]; trunk bent [30]; trunk bent and twisted [30]; exposure to whole body vibration [31]; also whether their work involved lifting or carrying at least $10 \mathrm{~kg}$ [30], 6 to $15 \mathrm{~kg}[32,33]$, and 16 to $25 \mathrm{~kg}[32,33]$. A question about lifting or carrying an object $>25 \mathrm{~kg}$ was modified from Viikari Juntura et al. [34].

Psychosocial exposures were assessed using the Job Content Questionnaire (JCQ) [35] and the short version of the Effort-Reward Imbalance (ERI) Questionnaire [36]. Information about job satisfaction was obtained by the Copenhagen Psychosocial Questionnaire II (COPSOQ II) [37]. An additional single question on perceived work stress was asked, "In general, how do you find your job?" A 5-point Likert scale was used for the response categories as follows: not at all stressful; mildly stressful; moderately stressful; very stressful; extremely stressful [38]. Organisational exposure was assessed by asking about current employment status (permanent; nonpermanent) and shift work (no shift work; shift work without a night shift; shift work with a night shift).

Questions about LBS and its consequences were asked using the Standardised Nordic Musculoskeletal Questionnaire [39]. LBS was defined as any symptoms (such as aches, pains, discomfort, numbness or fatigue) in the low back region during the last 12 month with symptoms more than 7 days and onset during the current job and also present within the last 7 days at the time of the survey. LBS' consequences were defined as symptoms preventing them from carrying out their normal activities (reduced activities) and if they had been absent from work due to those symptoms within the last 12 months (absenteeism). 


\subsection{Data analysis}

Before examining the interaction between physical and psychosocial factors, it was necessary to determine the criteria for high and low physical and psychosocial exposures. Univariate logistic regression was conducted to obtain the association between each explanatory factor and the outcomes. High exposures criteria were identified as those with an odds ratio (OR) significantly greater than 1 . Low exposure criteria were identified as those with an OR significantly less than 1 or with OR more than 1 and with its $95 \%$ CI including 1 . This analysis was conducted for both physical and psychosocial exposure.

To examine the interaction between physical and psychosocial risk factors, all participants were grouped into one of four combination exposure groups: 1) high physical and high psychosocial, 2) high physical and low psychosocial, 3) low physical and high psychosocial, 4) low physical and low psychosocial group (as the reference group). Workers that did not fulfil the criteria for classification into the high or low exposure groups were classified into an unclassified group and excluded from the analysis. Logistic regression was used to obtain the final model for combination of the risk factors. Organisational factors, age, and gender were included in the final model. The Hosmer-Lemeshow test was used to assess the fit of the final logistic regression model [40]. These analyses were carried out separately for each outcome (i.e. LBS, reduced activities, and absenteeism due to LBS). All statistical analyses were conducted using Predictive Analytics Software version 18.0 [41].

\section{Results}

Sixty three percent of workers $(n=825)$ completed the questionnaires. One hundred and fifty two workers did not meet the eligible criteria, i.e. had less than 1 year work experience in the current job, had had an accident involving the low back region previously, or answered less than $50 \%$ of the questions. Thus 673 questionnaires were considered to be valid and included in the present analysis.

Of the 673 valid questionnaires, 96\% were answered by males $(n=649)$ and $64 \%$ were aged $<30$ years $(n=434)$. The duration of work distributions were: $<3$ years - $40 \%(n=270) ; 3-5$ years $-28 \%$ $(n=188)$, and; $>5$ years $-32 \%(n=215)$. The prevalence of LBS (defined as any symptoms, such as aches, pains, discomfort, numbness or fatigue in the low back region, during the last 12 month with symptoms more than 7 days and onset during the current job and also present within the last 7 days at the time of the survey) was $23 \%$. The 12 -month period prevalence for reduced activities and absenteeism due to LBS were $19 \%$ and $17 \%$ respectively.

\subsection{Risk factors for $L B S$}

Working with a bent trunk $>50 \%$ of working time (OR 2.27, 95\% CI 1.01-5.18), exposure to whole body vibration $>50 \%$ of working time (2.94, 95\% CI 1.58-5.46), high effort (a score was above upper mean-based quartiles) (OR 2.07, 95\% CI 1.253.44), and having a very/extremely stressful job (OR $4.44,95 \%$ CI 2.00-9.85) significantly increased the risk of LBS after adjustment for age and gender. For organisational factors, being a non-permanent worker (OR 0.43, 95\% CI 0.28-0.66) was significantly associated with LBS.

Thus, the criteria for high physical exposures were trunk bent $>50 \%$ of working time and/or exposure to whole body vibration $>50 \%$ of working time. For low physical exposures the criteria were trunk bent $<50 \%$ of working time and/or exposure to whole body vibration $<50 \%$ of working time. The criteria for high psychosocial exposures were high effort (a score above upper mean-based quartiles) and/or having a very/extremely stressful job. For low psychosocial exposures criteria were low effort (a score below upper mean-based quartiles) and/or having a 'not at all' stressful job.

\subsection{Risk factors for reduced activities due to $L B S$}

Working with a bent trunk $>50 \%$ of working time (OR 2.43, 95\% CI 1.08-5.46), exposure to whole body vibration $>50 \%$ of working time (OR 2.35, 95\% CI 1.26-4.37), low reward (a score below lower mean-based quartiles) (OR 1.65, 95\% CI 1.072.56), and having a mildly/moderately stressful (OR $2.23,95 \%$ CI $1.22-4.06)$ or very/extremely stressful (OR 2.95, 95\% CI 1.13-7.69) job significantly increased the risk of reduced activities due to LBS after adjustment for age and gender. For organisational factors, being a non-permanent worker (OR 0.47, 95\% CI 0.29-0.77) and night shift work (OR 3.94, $95 \%$ CI 1.62-9.57) were significantly associated with reduced activities due to LBS.

Thus, the criteria for high physical exposures were trunk bent $>50 \%$ of working time and/or expo- 
sure to whole body vibration $>50 \%$ of working time. For low physical exposures criteria were trunk bent $<50 \%$ of working time and/or exposure to whole body vibration $<50 \%$ of working time. The criteria for high psychosocial exposures were low reward (a score below lower mean-based quartiles) and/or having ad mildly/moderately or very/extremely stressful job. For low psychosocial exposures criteria were low effort (a score was above upper meanbased quartiles) and/or having a 'not at all' stressful job.

\subsection{Risk factors for absenteeism due to $L B S$}

Exposure to whole body vibration $>50 \%$ of working time (OR 2.47, 95\% CI 1.28-4.74), lifting $>10 \mathrm{~kg}$, more than 50 times/day (OR 2.55, 95\% CI 1.11-5.87), having a mildly/moderately stressful job (OR 2.48, 95\% CI 1.26-4.90) significantly increased the risk of absenteeism due to LBS after adjustment for age and gender. For organisational factors, nonpermanent workers (OR $0.35,95 \%$ CI $0.21-0.59$ ), day shift work (OR 4.69, 95\% CI 1.80-12.23), and night shift work (OR 5.16, 95\% CI 1.55-17.13) were significantly associated with reduced activities due to LBS.

Thus, the criteria for high physical exposures were exposure to whole body vibration $>50 \%$ and/or working time and/or lifting $>10 \mathrm{~kg}$, more than 50 times/day; and for low physical exposures - exposure to whole body vibration $<50 \%$ of working time and/or $<50 \%$ and/or lifting $>10 \mathrm{~kg}$, less than 50 times/day. The criteria for high psychosocial exposures were having a mildly/moderately or very/extremely stressful job; and for low psychosocial exposures - having a 'not at all' stressful job.

\subsection{Interaction/combination of physical and psycho- social exposures}

For LBS, a total of 628 participants were classified into one of the four combination exposure groups with the distributions as follows: high physical and high psychosocial group $(n=144)$, high physical and low psychosocial group $(n=105)$, low physical and high psychosocial group $(n=250)$, and low physical and low psychosocial group $(n=129)$. Forty three participants were classified into an unclassified group and two questionnaires were missing.

For reduced activities due to LBS, a total of 624 participants were classified into one of the four combination exposure groups with the distributions as follows: high physical and high psychosocial group $(n=214)$, high physical and low psychosocial group $(n=33)$, low physical and high psychosocial group $(n=327)$, and low physical and low psychosocial group $(n=50)$. Forty eight participants were classified into an unclassified group and one questionnaire was missing.

For absenteeism due to LBS, a total of 609 participants were classified into one of the four combination exposure groups with the distributions as follows: high physical and high psychosocial group $(n=183)$, high physical and low psychosocial group $(n=57)$, low physical and high psychosocial group $(n=294)$, and low physical and low psychosocial group $(n=75)$. Sixty two participants were classified into an unclassified group and two questionnaires were missing.

In the final model, those in the high physical and high psychosocial group were the most likely to report LBS (OR 3.47 95\% CI 1.81-6.64), reduced activities (OR 6.94 95\% CI 1.58-30.49) and absenteeism (OR 7.01 95\% CI 2.04-24.10) (Table 1).

The results of the Hosmer-Lemeshow goodness of fit test were: $p=0.790$ for LBS; $p=0.959$ for reduced activities due to LBS, and; $p=0.383$ for absenteeism due to LBS, indicating that lack-of-fit was not large enough to reject the models.

\section{Table 1}

The final model of risk factors for LBS, reduced activities, and absenteeism due to LBS

\begin{tabular}{|c|c|c|}
\hline & ${ }^{\mathrm{a} O \mathrm{OR}}$ & $(95 \% \mathrm{CI})$ \\
\hline \multicolumn{3}{|l|}{ LBS } \\
\hline \multicolumn{3}{|l|}{ Physical and psychosocial exposure } \\
\hline low physical - low psychosocial & 1.00 & \\
\hline low physical - high psychosocial & 0.96 & $(0.50-1.85)$ \\
\hline high physical - low psychosocial & 3.44 & $(1.73-6.85)$ \\
\hline high physical - high psychosocial & 3.47 & $(1.81-6.64)$ \\
\hline \multicolumn{3}{|l|}{ Age } \\
\hline$<30$ & 1.00 & \\
\hline$\geq 30$ & 0.86 & $(0.54-1.38)$ \\
\hline \multicolumn{3}{|l|}{ Gender } \\
\hline Females & 1.00 & \\
\hline Males & 4.49 & $(0.57-35-27)$ \\
\hline \multicolumn{3}{|l|}{ Current employment status } \\
\hline Permanent employee & 1.00 & \\
\hline Non-permanent employee & 0.37 & $(0.23-0.60)$ \\
\hline \multicolumn{3}{|l|}{ Shift work } \\
\hline No shift work & N/A & \\
\hline \multicolumn{3}{|l|}{$\begin{array}{r}\text { Yes, but without night shift } \\
\text { Yes, with night shift }\end{array}$} \\
\hline \multicolumn{3}{|l|}{ Reduced activities } \\
\hline Physical and psychosocial exposure & & \\
\hline low physical - low psychosocial & 1.00 & \\
\hline low physical - high psychosocial & 3.10 & $(0.70-13.64)$ \\
\hline high physical - low psychosocial & 2.84 & $(0.46-17.28)$ \\
\hline high physical - high psychosocial & 6.94 & $(1.58-30.49)$ \\
\hline
\end{tabular}




\begin{tabular}{|c|c|c|}
\hline \multicolumn{3}{|l|}{ Age } \\
\hline$<30$ & 1.00 & \\
\hline$\geq 30$ & 1.32 & $(0.80-2.19)$ \\
\hline \multicolumn{3}{|l|}{ Gender } \\
\hline Females & 1.00 & \\
\hline Males & 3.51 & $(0.42-28.84)$ \\
\hline \multicolumn{3}{|l|}{ Current employment status } \\
\hline Permanent employee & 1.00 & \\
\hline Non-permanent employee & 0.45 & $(0.27-0.75)$ \\
\hline \multicolumn{3}{|l|}{ Shift work } \\
\hline No shift work & 1.00 & \\
\hline Yes, but without night shift & 2.46 & $(0.70-8.59)$ \\
\hline Yes, with night shift & 2.63 & $(1.03-6.73)$ \\
\hline \multicolumn{3}{|l|}{ Absenteeism } \\
\hline \multicolumn{3}{|l|}{ Physical and psychosocial exposure } \\
\hline low physical - low psychosocial & 1.00 & \\
\hline low physical - high psychosocial & 3.09 & $(0.89-10.62)$ \\
\hline high physical - low psychosocial & 3.27 & $(0.77-13.85)$ \\
\hline high physical - high psychosocial & 7.01 & (2.04-24.10) \\
\hline \multicolumn{3}{|l|}{ Age } \\
\hline$<30$ & 1.00 & \\
\hline$\geq 30$ & 1.28 & $(0.75-2.18)$ \\
\hline \multicolumn{3}{|l|}{ Gender } \\
\hline Females & 1.00 & \\
\hline Males & 1.52 & $(0.30-7.62)$ \\
\hline \multicolumn{3}{|l|}{ Current employment status } \\
\hline Permanent employee & 1.00 & \\
\hline Non-permanent employee & 0.37 & $(0.21-0.64)$ \\
\hline \multicolumn{3}{|l|}{ Shift work } \\
\hline No shift work & 1.00 & \\
\hline Yes, but without night shift & 3.13 & $(1.13-8.61)$ \\
\hline Yes, with night shift & 4.01 & $(1.21-14.35)$ \\
\hline
\end{tabular}

\section{Discussion}

Combined exposure to physical and psychosocial work risk factors increased the risk of LBS as well as both consequences (reduced activities and absenteeism) in the present study. The nature of combined exposure allowed us to characterise the interactions among exposures, but this is beyond the scope of this paper. Individuals with both high physical and high psychosocial exposures were most likely to report LBS. Although it is difficult to compare this finding with other studies due to differences in risk factor criteria and the natures of the populations studied, it is in agreement with cross-sectional studies among working populations in Sweden [14] and the UK [21, 26] and US Marines [27]. The present study also found that a high physical exposure played a more important role in reporting LBS, which is in line with previous studies $[21,26]$. Carayon et al. [42] proposed that job stress may increase muscle tension as well as reduce blood flow to the muscles which may limit the ability of the body to repair and heal from microtrauma in the musculoskeletal sys- tem. This condition may be even worse among those who also have physical exposure. With respect to behaviour, individuals who experience stress in their job might be more likely to report musculoskeletal symptoms (MSS) or have lack of motivation to seek help [42]. Hence, it makes sense that those with high physical and also high psychosocial exposure had the highest risk of LBS.

Although those with both high physical and high psychosocial exposures were most likely to report LBS consequences, exposure to high physical and low psychosocial as well as exposure to low physical and high psychosocial did not increase the risk of LBS' consequences. Interestingly, without combining the physical and psychosocial exposure, i.e. exposure to either physical or psychosocial risk factors alone, significantly increased the risk of LBS consequences. For example, the univariate analysis for each risk factor showed that working with trunk bent, exposure to whole body vibration, low reward, and work stress significantly increased the risk of reduced activities due to LBS after adjustment for age and gender. But, workers with a combined exposure, i.e. high physical and low psychosocial (e.g. working with trunk bent and/or exposure to whole body vibration but with high reward and/or perceiving that the job was not at all stressful) or vice versa, the risk of reporting LBS consequences did not increase.

It is therefore speculated that a good psychosocial working condition may buffer the negative effect of a poor physical working condition on the risk of LBS consequences, and vice versa. This means that working in a poor physical working condition (e.g. working with a trunk bent, exposure to whole body vibration, and doing lifting) may increase the risk of reporting LBS consequences, but this risk may be reduced if the workers are also working in a good psychosocial working environment. This speculation is supported by Joling et al.'s study [43] among 1552 Dutch workers which showed that among those with high physical workload, those who experienced a good psychosocial environment (i.e. a high quality of communication) had a lower risk of work-related MSS compared to those who experienced a poor psychosocial environment (i.e. a low quality of communication). Also, among those with low physical workload, those who experienced a poor psychosocial environment (i.e. a low quality of communication) had a higher risk of work related MSS compared to those who also experienced a good psychosocial environment (i.e. a high quality of communication) [43]. The findings from Torp et al.'s [44] and 
Torp et al.'s [45] studies that investigated the influence of psychosocial work environment in coping with MSS among mechanics may also strengthen our speculation. These studies found that there were positive and significant relationships between psychosocial factors and how mechanics coped with their MSS. The higher social support and manager's involvement in health and safety that the mechanics experienced, the more often they used many coping strategies to reduce their MSS (e.g. the use of equipment to reduce the physical strain, changes in working technique, discussing the problem with the health and safety deputy). This condition, in turn, will reduce the MSS reported and/or avoid progression towards more severe symptoms among the workers. Hence, it makes sense that in the present study there is no increasing risk of LBS' consequences (which might be due to severe condition of LBS) amongst those who were exposed to poor physical working conditions but were exposed to good psychosocial working conditions. However, since there appear to be only a few studies that have investigated combination/interaction between physical and psychosocial and LBS, it is difficult to reach any firm conclusion. Since workers are often simultaneously exposed to both physical and psychosocial factors in the workplace, it is an issue that may warrant further investigation.

The present study also showed that being a nonpermanent employee was a protective factor for LBS and absenteeism due to LBS. This finding is supported by a previous cross-sectional study in a German population [23]. Schneider et al. [23] hypothesed that full-time workers (permanent employees) were more likely to be exposed to risk factors at work (due to a longer working time and period of employment) and were more likely to report LBS than part-time workers (non-permanent employees). Additionally, absenteeism, expressed as the number of days absent from work, is one of the key performance indicators that commonly influence the salary for non-permanent employee. If it is assumed that part-time workers suffering from severe LBS tend not to take sick leave due to concerns about their job security, it seems likely that non-permanent employees will be less likely to report absenteeism due to LBS.

In the present study, night shift workers had a higher risk of LBS consequences than non-shift workers. Night shifts have been shown to be associated with short or disturbed sleep [46, 47]. This may reduce the production of the hormone that stimulates anabolism to assist musculoskeletal tissue regeneration [48]. This hypothesis is also supported by Jansen et al. [49] who found that shift workers had a higher OR for an elevated need for recovery compared to non-shift workers. Additionally, Theorell et al. [50] proposed that disturbed sleep may increase muscle tension which can lead to pain in the low back region.

Although the large sample size in the present study allowed us to explore the interaction between physical and psychosocial factors by classifying them into four combination exposure groups, the confidence intervals around the risk estimates for LBS consequences were wide. Hence, a larger sample size may be necessary to obtain more appropriate estimations for such an analysis.

In order to conduct a survey with such a large sample it was necessary to use a self-administered questionnaire method for practical reasons [51, 52]. This method is known to provide valid and reliable data [39]. However, the use of self-report questionnaires has been criticised for not providing accurate information due to recall bias. Recall inconsistencies are more likely among those with less serious LBS [39]. Therefore, selecting those who had LBS during the last 12 months with symptoms more than 7 days and onset during their current job and also present within the last 7 days at the time of survey in the analysis is likely to have reduced the possibility of recall bias in the present study. In addition, a good agreement between self-reported absenteeism and absence recorded for a recall period of 12 months [53] indicates that recall bias regarding self-reported absenteeism appears to be unlikely.

Analyses based on cross-sectional studies cannot be used to make causal inferences. The association between risk factors and LBS and its consequences reported in the present study may have been biased due to the selection processes used to identify the participants (i.e. a healthy worker effect). Hence, longitudinal studies are needed to reach firm conclusions about the causal relationship between LBS and its risk factors $[54,55]$.

In conclusion, the present study has shown that Indonesian coal mining workers with both high physical and high psychosocial exposures were most likely to report LBS and its consequences. Permanent workers were more likely to report LBS and its consequences whereas night shift work increased the risk of LBS consequences. The findings imply that efforts to reduce LBS and its consequences in the workplace in the coal mining industry in Indonesia should ad- 
dress both physical factors (i.e. reducing working with a bent trunk posture, whole body vibration exposure, and lifting) and psychosocial factors (i.e. reducing the worker's effort, increasing reward and managing work stress) with a focus on permanent employees and night shift workers. It is logical to suppose that similar conclusions might apply for other industries in other IDCs.

\section{Acknowledgements}

We acknowledge funding support from Directorate General of Higher Education Overseas Postgraduate Scholarship Program, Department of National Education, Indonesia and Postgraduate Student Support, School of Management, Massey University, New Zealand. We would like to thank Rahmadani Arnur, BScPH and Dimas Ari Dharmawirawan, $\mathrm{BScPH}$, who conducted the data collection and completed the data entry, and also Setyo Rohadi, MD, MOHS, who managed hosting during the survey.

\section{References}

[1] W.E. Hoogendoorn, P.M. Bongers, H.C.W. de Vet, M. Douwes, B.W. Koes, M.C. Miedema, G.A.M. Ariens, L.M. Bouter, Flexion and rotation of the trunk and lifting at work are risk factors for low back pain - Results of a prospective cohort study, Spine, 25 (2000) 3087-3092.

[2] W.E. Hooftman, A.J. van der Beek, P.M. Bongers, W. van Mechelen, Is there a gender difference in the effect of workrelated physical and psychosocial risk factors on musculoskeletal symptoms and related sickness absence?, Scan J Work Environ Health, 35 (2009) 85-95.

[3] G. Engholm, E. Holmström, Dose-response associations between musculoskeletal disorders and physical and psychosocial factors among construction workers, Scan J Work Environ Health, 31 (2005) 57-67.

[4] W. Ijzelenberg, D. Molenaar, A. Burdorf, Different risk factors for musculoskeletal complaints and musculoskeletal sickness absence, Scan J Work Environ Health, 30 (2004) 56-63.

[5] U. Aasa, M. Barnekow-Bergvist, K.-A. Angquist, C. Brulin, Relationship between work-related factors and disorders in the neck-shoulder and low-back region among female and male ambulance personnel, J Occup Health, 47 (2005) 481489.

[6] M. Simon, P. Tackenberg, A. Nienhaus, M. Estryn-Behar, P.M. Conway, H.M. Hasselhorn, Back or neck-pain-related disability of nursing staff in hospitals, nursing homes and home care in seven countries-results from the European NEXT-Study, International Journal of Nursing Studies, 45 (2008) 24-34

[7] W.E. Hoogendoorn, P.M. Bongers, H.C.W. de Vet, G.A.M Ariëns, W. van Mechelen, L.M. Bouter, High physical work load and low job satisfaction increase the risk of sickness absence due to low back pain: results of a prospective cohort study, Occupational and Environmental Medicine, 59 (2002) 323-328.

[8] F. Tubach, A. Leclerc, M.F. Landre, F. Pietri-Taleb, Risk factors for sick leave due to low back pain: A prospective study, Journal of Occupational and Environmental Medicine, 44 (2002) 451-458.

[9] J. Alcouffe, P. Manillier, M. Brehier, C. Fabin, F. Faupin, Analysis by sex of low back pain among workers from small companies in the Paris area: severity and occupational consequences, Occupational and Environmental Medicine, 56 (1999) 696-701.

[10] L.A.M. Elders, A. Burdorf, Interrelations of risk factors and low back pain in scaffolders, Occupational and Environmental Medicine, 58 (2001) 597-603.

[11] L. Lei, P.G. Dempsey, J.-g. Xu, L.-n. Ge, Y.-x. Liang, Risk factors for the prevalence of musculoskeletal disorders among chinese foundry workers, International Journal of Industrial Ergonomics, 35 (2005) 197-204.

[12] H. Miranda, E. Viikari-Juntura, L. Punnett, H. Riihimaki, Occupational loading, health behavior and sleep disturbance as predictors of low-back pain, Scan J Work Environ Health, 34 (2008) 411-419.

[13] A. Burdorf, H. Zondervan, An epidemiologic study of lowback pain in crane operators, Ergonomics, 33 (1990) 981987.

[14] S.J. Linton, Risk-factors for neck and back pain in a working population in Sweden, Work and Stress, 4 (1990) 41-49.

[15] M. Bovenzi, I. Pinto, N. Stacchini, Low back pain in port machinery operators, Journal of Sound and Vibration, 253 (2002) 3-20

[16] H. Hemingway, M.J. Shipley, S. Stansfeld, M. Marmot, Sickness absence from back pain, psychosocial work characteristics and employment grade among office workers, Scan J Work Environ Health, 23 (1997) 121-129.

[17] W.E. Hoogendoorn, P.M. Bongers, H.C. de Vet, I.L. Houtman, G.A. Ariëns, W. van Mechelen, L.M. Bouter, Psychosocial work characteristics and psychological strain in relation to low-back pain, Scan J Work Environ Health, 27 (2001) 258-267.

[18] S.G. van den Heuvel, G.A.M. Ariens, H.C. Boshuizen, W.E. Hoogendoom, P.M. Bongers, Prognostic factors related to recurrent low-back pain and sickness absence, Scan J Work Environ Health, 30 (2004) 459-467.

[19] M. Ghaffari, A. Alipour, A.A. Farshad, I. Jensen, M. Josephson, E. Vingard, Effect of psychosocial factors on low back pain in industrial workers, Occupational MedicineOxford, 58 (2008) 341-347.

[20] R. Rugulies, N. Krause, Effort-reward imbalance and incidence of low back and neck injuries in San Francisco transit operators, Occupational and Environmental Medicine, 65 (2008) 525-533.

[21] J. Devereux, L. Rydstedt, V. Kelly, P. Weston, P. Buckle, The role of work stress and psychological factors in the development of musculoskeletal disorders: The stress and MSD study (RR 273), in, Health and Safety Executive. http://www.hse.gov.uk/research/rrhtm/rr273.htm, 2004.

[22] J.A. Lipscomb, A.M. Trinkoff, J. Geiger-Brown, B. Brady, Work-schedule characteristics and reported musculoskeletal disorders of registered nurses, Scan J Work Environ Health, 28 (2002) 394-401.

[23] S. Schneider, M. Schiltenwolf, S.M. Zoller, H. Schmitt, The association between social factors, employment status and self-reported back pain - A representative prevalence study on the German general population, Journal of Public Health, 13 (2005) 30-39. 
[24] K.G. Davis, C.A. Heaney, The relationship between psychosocial work characteristics and low back pain: underlying methodological issues, Clinical Biomechanics, 15 (2000) 389-406.

[25] B.-T. Karsh, Theories of work-related musculoskeletal disorders: Implications for ergonomic interventions, Theoretical Issues in Ergonomics Science, 7 (2006) 71-88.

[26] J.J. Devereux, P.W. Buckle, I.G. Vlachonikolis, Interactions between physical and psychosocial risk factors at work increase the risk of back disorders: an epidemiological approach, Occupational and Environmental Medicine, 56 (1999) 343-353.

[27] G.D. Huang, M. Feuerstein, W.J. Kop, K. Schor, F. Arroyo, Individual and combined impacts of biomechanical and work organization factors in work-related musculoskeletal symptoms, American Journal of Industrial Medicine, 43 (2003) 495-506

[28] J. Lapointe, C.E. Dionne, C. Brisson, S. Montreuil, Interaction between postural risk factors and job strain on self-reported musculoskeletal symptoms among users of video display units: a three-year prospective study, Scan J Work Environ Health, 35 (2009) 134-144.

[29] D.E. Beaton, C. Bombardier, F. Guillemin, M.B. Ferraz, Guidelines for the process of cross-cultural adaptation of self-report measures, Spine, 25 (2000) 3186-3191.

[30] O. Leijon, C. Wiktorin, A. Harenstam, L. Karlqvist, MOA Research Group, Validity of a Self-Administered Questionnaire for Assessing Physical Work Loads in a General Population, Journal of Occupational and Environmental Medicine, 44 (2002) 724-735.

[31] C. Wiktorin, E.W. Hjelm, J. Winkel, M. Koster, Reproducibility of a questionnaire for assessment of physical load during work and leisure time, Journal of Occupational and Environmental Medicine, 38 (1996) 190-201.

[32] M. Torgen, L. Alfredsson, M. Koster, C. Wiktorin, K.F. Smith, A. Kilbom, Reproducibility of a questionnaire for assessment of present and past physical activities, International Archives of Occupational and Environmental Health, 70 (1997) 107-118

[33] C. Wiktorin, E. Vingard, M. Mortimer, G. Pernold, E. Wigaeus-Hjelm, A. Kilbom, L. Alfredsson, M.N.S. Grp, Interview versus questionnaire for assessing physical loads in the population-based MUSIC-Norrtalje study, American Journal of Industrial Medicine, 35 (1999) 441-455.

[34] E. Viikari Juntura, S. Rauas, R. Martikainen, E. Kuosma, H. Riihimaki, E.P. Takala, K. Saarenmaa, Validity of selfreported physical work load in epidemiologic studies on musculoskeletal disorders, Scan J Work Environ Health, 22 (1996) 251-259.

[35] R. Karasek, C. Brisson, N. Kawakami, I. Houtman, P. Bongers, B. Amick, The Job Content Questionnaire (JCQ): An Instrument for Internationally Comparative Assessments of Psychosocial Job Characteristics, Journal of Occupational Health Psychology, 3 (1998) 322-355.

[36] J. Siegrist, N. Wege, F. Pühlhofer, M. Wahrendorf, A short generic measure of work stress in the era globalization: efforreward imbalance, Int Arch Occup Environ Health, 82 (2008) 1005-1013.

[37] J.H. Pejtersen, T.S. Kristensen, V. Borg, J.B. Bjorner, The second version of the Copenhagen Psychosocial Questionnaire, Scandinavian Journal of Public Health, 38 (2010) 8-24.

[38] A. Smith, S. Johal, E. Wadsworth, G. Davey Smith, I. Harvey, T. Peters, The scale of occupational stress, Occup Health Review, 73 (1998) 19-22.
[39] I. Kuorinka, B. Jonsson, A. Kilbom, H. Vinterberg, F. Biering-Sørensen, G. Andersson, K. Jørgensen, Standardised Nordic questionnaires for the analysis of musculoskeletal symptoms, Applied Ergonomics, 18 (1987) 233-237.

[40] D.W. Hosmer, S. Lemeshow, Applied Logistic Regression, 2nd ed., John Wiley \& Sons, New York, 2000.

[41] Predictive Analytics Software (PASW) Statistics 18, Release 18.0.0, in, SPSS Inc., an IBM Company, Chicago, 2009.

[42] P. Carayon, M.J. Smith, M.C. Haims, Work organization, job stress, and work-related musculoskeletal disorders, Human Factors, 41 (1999) 644-663.

[43] C. Joling, B. Blatter, J. Ybema, P. Bongers, Can favorable psychosocial work conditions and high work dedication protect against the occurrence of work-related musculoskeletal disorders?, Scan J Work Environ Health, 34 (2008) 345-355.

[44] S. Torp, T. Riise, B.E. Moen, How the psychosocial work environment of motor vehicle mechanics may influence coping with musculoskeletal symptoms, Work and Stress, 13 (1999) 193-203.

[45] S. Torp, T. Riise, B.E. Moen, The impact of social and organizational factors on workers' coping with musculoskeletal symptoms, Physical Therapy, 81 (2001) 1328-1338.

[46] M. Härmä, Workhours in relation to work stress, recovery and health, Scan J Work Environ Health, 32 (2006) 502-514.

[47] L. van Amelsvoort, N.W. Jansen, G.M. Swaen, P. van den Brandt, I. Kant, Direction of shift rotation among three-shift workers in relation to psychological health and work-family conflict, Scandinavian J Work Environment \& Health, 30 (2004) 149-156.

[48] T. Theorell, Possible mechanisms behind the relationship between the demand-control-support model and disorders of the locomotor system, in: S.D. Moon, S.L. Sauter (Eds.) Beyond biomechanics : psychosocial aspects of musculoskeletal disorders in office work, Taylor \& Francis, London ; Bristol, PA, 1996, pp. 65-73.

[49] N.W.H. Jansen, I. Kant, L. van Amelsvoort, F.J.N. Nijhuis, P. van den Brandt, Need for recovery from work: evaluating short-term effects of working hours, patterns and schedules, Ergonomics, 46 (2003) 664-680.

[50] T. Theorell, K. Harms-Ringdahl, G. Ahlberg-Hulten, B. Westin, Psychosocial job factors and symptoms from the locomotor system - a multicausal analysis, Scand J Rehabil Med, 23 (1991) 165-173.

[51] K.J. Rothman, S. Greenland, T.L. Lash, Modern Epidemiology, Third ed., Lippincott Williams \& Wilkins, Philadelphia, 2008.

[52] E. White, B.K. Armstrong, R. Saracci, Principles of Exposure Measurement in Epidemiology: Collecting, Evaluating, and Improving Measures of Disease Risk Factors, 2nd ed., Oxford University Press, New York, 2008.

[53] J.E. Ferrie, M. Kivimäki, J. Head, M. Shipley, J. Vahtera, M. Marmot, A comparison of self-reported sickness absence with absences recorded in employers' registers: evidence from the Whitehall II study, Occupational and Environmental Medicine, 62 (2005) 74-79.

[54] H.M. Arrighi, I. Hertzpicciotto, The evolving concept of the healthy worker survivor effect, Epidemiology, 5 (1994) 189196.

[55] J. Hartvigsen, L.S. Bakketeig, C. Leboeuf-Yde, M. Engberg, T. Lauritzen, The Association Between Physical Workload and Low Back Pain Clouded by the "Healthy Worker" Effect, Spine, 26 (2001) 1788-1793. 